\title{
Surgical Management Strategies in Patients with Primary Hyperparathyroidism: Which Technique in Which Patients?
}

\author{
Ayhan Koyuncu $^{a}$ Hatice Sebila Dökmetaş ${ }^{b}$ Cengiz Aydın ${ }^{a}$ Mustafa Turan ${ }^{a}$ \\ Taner Erselcan $^{c}$ Selçuk Sözeri ${ }^{a}$ Metin Şen $^{a}$ \\ Departments of a General Surgery, ${ }^{b}$ Endocrinology and ${ }^{c}$ Nuclear Medicine, Faculty of Medicine, \\ Cumhuriyet University, Sivas, Turkey
}

\section{Key Words}

Primary hyperparathyroidism $\cdot$ Hypercalcemia $\cdot$

Surgery - Unilateral neck exploration - Bilateral neck

exploration $\cdot$ Sestamibi scintigraphy

\begin{abstract}
Objective: This study was planned to investigate the efficacy of either ${ }^{99 m}$ Tc-sestamibi scan or ultrasonography in predicting the operative treatment in patients with primary hyperparathyroidism (PHPT). Subjects and Method: Thirty patients (25 female, 5 male; mean age: 53 years) being operated for symptomatic primary PHPT were included in this study. Ultrasonography was used in 29 patients while ${ }^{99 m}$ Tc-sestamibi scintigraphy was done in 28 patients to localize the hyperfunctioning gland(s). Standard bilateral neck exploration was done in 6 patients. Although unilateral intervention had been planned for 24 patients, bilateral intervention was performed in 9 of them. Results: Sensitivity of ${ }^{99 \mathrm{~m}}$ Tc-sestamibi was $81 \%$, while that of ultrasonography was $42 \%$. ${ }^{99 m}$ Tc-sestamibi localization method led to misleading results in 10/28 (35.7\%) patients. False-positive localization and accompanying thyroid pathologies played an important role in determining transition from unilateral
\end{abstract}

to bilateral intervention. Conclusion: Our findings indicate that bilateral intervention remains a successful management option without prior localization in patients with PHPT especially in an endemic goiter region.

Copyright $(2005$ S. Karger AG, Basel

\section{Introduction}

Primary hyperparathyroidism (PHPT) is an endocrine disorder characterized by abnormal parathormone $(\mathrm{PTH})$ release and hypercalcemia [1]. PHPT is the most common etiological factor for hypercalcemia with a prevalence of $0.1-0.5 \%$ [2-5]. Its expected incidence is 1 in 1,000 male and $2-3$ in 1,000 female subjects [6]. The disease affects postmenopausal women, peaking in the 5 th and 6th decades. Its male:female ratio is 1:3 [7].

The definitive treatment of symptomatic patients is the extraction of the abnormal gland(s). Currently, it is possible to find asymptomatic cases through routine measurement of serum calcium using multichannel serum analyzers [8]. Half of the asymptomatic cases can be detected without surgical intervention. NIH consensus conference determined the indications for surgery [9].

\section{KARGER}

Fax +4161306 1234

E-Mail karger@karger.ch

www.karger.com
(C) 2005 S. Karger AG, Basel

1011-7571/05/0143-0194\$22.00/0

Accessible online at:

www.karger.com/mpp
Dr. Ayhan Koyuncu

Department of General Surgery

Faculty of Medicine, Cumhuriyet University

TR-58140 Sivas (Turkey)

Tel. +90 $3462191300 / 2145$, Fax +90 346 2191284, E-Mail akoyuncu@cumhuriyet.edu.tr 
Bilateral neck operation, defined as finding the four glands and extracting the hyperfunctioning ones, is the accepted gold standard in surgical treatment of PHPT [10]. Nowadays, the idea of surgical intervention to remove only the abnormal gland is becoming important due to the abundance of nonsurgical localization methods. Scintigraphy, ultrasonography (US) and intraoperative nuclear scanning methods can be used for localization. However, there is controversy about the methods and their diagnostic values. Unilateral neck exploration together with a localization method is usually sufficient to cure adenoma-related disease in $80-90 \%$ of the cases [11-13]. Latest reports have provided evidence diminishing the importance of nonsurgical localization methods $[14,15]$. Equally the probability of multiple gland disease cannot be excluded.

Hence, we decided to investigate the efficacy of either ${ }^{99 \mathrm{~m}} \mathrm{Tc}$-sestamibi scintigraphy or US in predicting surgical treatment for patients with PHPT.

\section{Subjects and Methods}

Thirty patients operated for PHPT were included in the study. Data were collected through a prospectively maintained longitudinal database along with retrospective chart review. Informed consent was obtained from all the patients according to the criteria of our Institutional Human Subject Research Committee. The diagnosis of PHPT was based on the following criteria: calcium levels $>10.5 \mathrm{mg} / \mathrm{dl}$, intact PTH levels $>65 \mathrm{pg} / \mathrm{ml}$, increase in urinary calcium excretion, decrease in serum phosphorus levels and excluding past history of familial hypocalciuric hypercalcemia or lithium administration. All the patients were symptomatic.

US (Toshiba Power Vision 6000 5-7.5 mega prob, Japan) was performed in 29 patients while technetium- $99 \mathrm{~m}$ methoxyisobutylisonitrile $\left({ }^{99 \mathrm{~m}} \mathrm{Tc}\right.$-sestamibi) scintigraphy was available in 28. Dynamic and static images were acquired after administration of $740 \mathrm{MBq}(20 \mathrm{mCi}){ }^{99 \mathrm{~m}} \mathrm{Tc}$-sestamibi using a pinhole camera (MG 11 Orbiter, M1G), dynamic images (15 per minute) in $128 \times 128$ matrices, and static image was acquired $2 \mathrm{~h}$ later. The results were expressed as true positive when the enlarged gland was conveniently localized during operation.

ILab 1800 autoanalyzer (Lexington, USA) was used to determine renal function, calcium, phosphorus and alkaline phosphates pre- and postoperatively in the patients. Intact PTH measurements were performed by using an automated analyzer device (Immulite, Diagnostic Products, Los Angeles, Calif., USA). Daily urinary calcium excretions were recorded from 24-hour urinary samples.

If a hyperfunctioning parathyroid gland was localized, unilateral intervention was performed. During intervention, when a large gland representing large adenoma by gross appearance was found, it was surgically extracted and sent for histopathological confirmation. If the indicated gland was normal in size, ipsilateral and contralateral parathyroid glands were explored sequentially. Subtotal parathyroidectomy was performed if all parathyroid glands were
Table 1. Symptoms and signs of patients with PHPT

\begin{tabular}{lrc}
\hline Symptom/sign & $\mathrm{n}$ & $\%$ \\
\hline Exhaustion & 23 & 76.6 \\
Muscle weakness & 22 & 73.3 \\
Bone pain & 12 & 40.0 \\
Dyspeptic complaints & 26 & 86.6 \\
Polyuria, polydipsia & 11 & 36.6 \\
Bone fracture & 5 & 16.6 \\
Brown tumor & 7 & 23.3 \\
Nephrolithiasis & 13 & 43.3 \\
Hypertension & 14 & 48.2 \\
\hline
\end{tabular}

larger than normal size, macroscopically suggesting hyperplasia. Bilateral intervention was done if the parathyroid gland was not localized or in patients with accompanying thyroid pathologies. If four parathyroid glands on each side were seen in bilateral exploration, the biggest one was extracted and sent to frozen section for confirmation. The decision to stop surgical exploration was based on the macroscopic appearances of glands.

Patients with accompanying thyroid disease also received intervention for the extra pathologies. Patients showing thyroid nodule preoperatively were also investigated for malignancy.

The patients were followed up for postoperative complications and hypocalcemia. Preoperative and intraoperative localizations were compared by means of diagnostic sensitivities. Patients having bilateral intervention were compared with respect to hospitalization periods and development of complications.

The results were expressed as mean \pm standard error. The formula [true positives/(true positives + false negatives)] $\times 100$ was used to determine the diagnostic sensitivities of scintigraphy and US. True positives were defined as patients whose localization and surgical findings were congruent, and false negatives were defined as patients having negative localization before surgery, but parathyroidal pathology was found intraoperatively; $t$ test was used for statistical analysis with a value of $p<0.05$ accepted as significant.

\section{Results}

\section{Clinical and Laboratory Findings}

Twenty-five patients were female $(83.3 \%)$ and 5 were male (16.6\%) with an average age of 53 (28-73 years). Nodular goiter was found in 11 of the patients by physical examination. Subperiosteal bone resorption and saltpaper appearance were found in direct graphics in 11 patients and brown tumors were observed in 7 patients. Symptoms and signs of the patients are shown in table 1 . None of the patients had hypoalbuminemia. Mean serum absolute calcium concentration was $11.3 \pm 0.8 \mathrm{mg} / \mathrm{dl}$ 
(8.4-10.2 mg/dl); phosphorus $2.5 \pm 0.8 \mathrm{mg} / \mathrm{dl}(2.7-$ $4.5 \mathrm{mg} / \mathrm{dl})$; intact PTH $437.7 \pm 484.6 \mathrm{pg} / \mathrm{ml}(7-53 \mathrm{pg} /$ $\mathrm{ml}$ ); alkaline phosphates $356.2 \pm 558.1 \mathrm{U} / \mathrm{l}(42-141 \mathrm{U} / \mathrm{l})$, and 24-hour urinary excretion of calcium $428.0 \pm$ $185.1 \mathrm{mg} /$ day $(<250 \mathrm{mg} /$ day $)$.

\section{Localization Studies}

For ${ }^{99 \mathrm{~m}}$ Tc-sestamibi scintigraphy in the 28 patients, the true-positive, false-positive and false-negative cases were 18, 6 and 4, respectively. In true-positive cases, the adenomas were localized at the right inferior in 9, left inferior in 7 and right superior in 2. Diagnostic sensitivity of ${ }^{99 \mathrm{~m}} \mathrm{Tc}$-sestamibi scintigraphy was $81 \%$. In case of US, in the 29 patients, true-positive, false-positive and falsenegative were in 11,3 and 15 cases, respectively. The sensitivity of the technique was $42 \%$.

\section{Surgical Findings}

Of the 30 patients, 15 each had bilateral or unilateral intervention, although unilateral intervention had been planned for 24 patients preoperatively, but it became necessary to do bilateral intervention in 9 . Of the 9 patients with negative ${ }^{99 \mathrm{~m}} \mathrm{Tc}$ scintigraphy, 6 had bilateral intervention. Parathyroid hyperplasia was found in $2 / 6$. In $1 / 6$ patients, although ${ }^{99 \mathrm{~m}}$ Tc-sestamibi scintigraphy demonstrated an adenoma in the right inferior, the indicated lesion was not found during bilateral interventions. Elevated serum calcium levels persisted after operation in this patient. Subsequently, the parathyroid adenoma was found in the mediastinum by radio-guided gamma probe in the second operation and postoperative serum calcium levels of this patient returned to normal. Adenoma was found in another localization in the remaining 3/6 patients. In addition, $3 / 9$ patients had bilateral thyroidal nodular disease. Bilateral intervention was initially planned in 6 patients, because of negative (4/6) or lacking scintigraphy $(2 / 6)$.

We observed failure after the first surgical intervention in 1 patient (3.3\%), but this patient was successfully treated later in a second operation. Thus all of the cases were successfully treated. Hospitalization periods of patients with unilateral and bilateral intervention were $2.9 \pm 1.2$ and $3.3 \pm 1.1$ days $(p=0.35)$, respectively.

Decreases in serum calcium levels were observed at 24-48 $\mathrm{h}$ after operation. All of the patients received calcium treatment. Calcium and vitamin D treatment were given for longer periods to 8 patients as hungry-bone syndrome developed. None of the patients experienced either persistent hypocalcemia or transient or persistent recurrent nerve damage.
Table 2. Free $T_{3}$, free $T_{4}$ and sensitive $T S H$ values of the patients

\begin{tabular}{lll}
\hline & Patients' values & Normal values \\
\hline Free $\mathrm{T}_{4}, \mathrm{ng} / \mathrm{dl}$ & $2.44 \pm 0.53$ & $1.45-3.48$ \\
Free $_{3}, \mathrm{pg} / \mathrm{ml}$ & $1.10 \pm 0.28$ & $0.17-1.85$ \\
Sensitive TSH, $\mu \mathrm{IU} / \mathrm{ml}$ & $1.49 \pm 1.17$ & $0.49-4.67$ \\
\hline
\end{tabular}

\section{Accompanying Thyroid Disease}

Nine of the patients who had bilateral intervention had thyroid pathology. Of these 1 patient had Graves' disease, another had toxic multinodular goiter and the remaining 7 patients euthyroid nodular disease. All patients were euthyroid before surgery (table 2). Nearly total thyroidectomy was done on these patients. Unilateral nodular thyroid disease was present in 4 of the unilateral intervention patients. Total lobectomy was done on the lobe with the parathyroid pathology.

\section{Pathological Results}

Of the 30 patients, 28 were diagnosed with parathyroid adenoma while hyperplasia was found in only 2 . Thyroid malignancy was not found in any of the 30 patients.

\section{Discussion}

PHPT defined as a disease characterized by nephrolithiasis in over $50 \%$ of cases and osteitis fibrosa cystica in $25 \%$ of cases was not common in the past [16]. With the determination of blood hypercalcemia PHPT is readily detectable and may be asymptomatic and therefore may be more common than previously thought. More recently many patients are diagnosed with PHPT but without major findings of renal and skeletal system involvement, osteitis fibrosa cystica and nephrolithiasis ratio of 15$20 \%[17,18]$. In our series the patients were symptomatic as shown in table 1 and in our previous study in which Helicobacter pylori infection was significantly higher in PHPT patients $(94.4 \%)$ than in our dyspeptic control group [19].

The definitive treatment of symptomatic PHPT is surgery. After extraction of the adenomatous or hyperplastic parathyroid tissues, PTH level returns to normal. Bilateral neck exploration investigating the four glands and extraction of hyperfunctioning glands are accepted as the gold standard for surgical therapy with high success rate [20]. Generally, preoperative localization is not required 
for bilateral neck operation [21]. In our study, the total surgical success rate was $96.6 \%$, thereby confirming the previous reports $[22,23]$.

Our findings of $93 \%$ parathyroid pathology leading to PHPT are similar to $80-90 \%$ single adenoma reported previously $[11,12]$. Extracting adenoma in these cases is usually sufficient for therapy. For this reason some investigators support the idea that unilateral neck exploration is sufficient for PHPT [20, 24]. This procedure can be successful by using preoperative localization methods and/or perioperative gamma hand probe [22, 23, 25]. In addition, intraoperative PTH measurement has been suggested to be useful in excluding multiglandular disease [13]. Unilateral neck exploration can also be done videoassisted or completely by endoscopic interventions. Although bilateral neck exploration has a high cure rate and low morbidity in experienced centers, the trend is towards minimizing intervention. The purpose of minimal invasive intervention is making the incision smaller, decreasing the exploration area, decreasing hospitalization duration and costs [26].

Hyperfunctioning adenoma should be localized for unilateral intervention. Various methods have been used, but none has $100 \%$ diagnostic value [6]. The sensitivity of thallium-technetium is between 36 and $76 \%$ [27, 28]. ${ }^{99 m}$ Tc-sestamibi scintigraphy was reported to show parathyroidal pathology with 90-95\% sensitivity [29]. In our study this sensitivity was found to be $81 \%$ while this ratio was $42 \%$ for US.

The most important problem between unilateral and bilateral interventions is the possibility of overlooking multiglandular disease in unilateral intervention. Indeed, in one meta-analysis, while multiglandular disease ratio was $20 \%$ in bilateral intervention, this ratio was $5 \%$ in unilateral intervention [30]. Although it was reported that the measurement of intraoperative PTH level is not a very reliable test as it is emphasized that a premature decrease in PTH can be observed when only one abnormal gland is extracted [30], in a recent review the intraoperative PTH assay was found to be a useful adjunct to preoperative imaging and parathyroid surgery because of its unique ability to detect an occult hyperfunctioning parathyroid tissue [31]. It was also stated that the use of this assay would obviate the need for frozen section histopathology review in most routine cases. The test facilitates minimally invasive parathyroidectomy for single parathyroid adenomas, which, in turn, improves cost-effectiveness and cosmetic outcome. Its use in patients with known preoperative multiglandular disease is promising but requires further study [31]. In a recent study, it was reported that intraoperative PTH measurement allowed differentiation of single- from multiple-gland disease [32]. We could not measure the PTH levels intraoperatively because of lack of capacity in our laboratory.

It was reported that there were 67 patients with PHPT and concomitant thyroid disease out of 137 patients (49\%) in an endemic goiter region. This study emphasized that the localization methods were less sensitive in the patients having thyroid disease. However, combination of sestamibi and US seems most promising in patients with PHPT for localizing an enlarged parathyroid gland and without missing concomitant thyroid disease; this would make it possible to perform minimally invasive parathyroidectomy in the majority of patients suffering from PHPT in an endemic goiter region [33]. In our study, thyroid pathology was also present in a total of 13 patients $(43.3 \%)$ and we performed thyroidectomy according to thyroid disease type and localization. There was not any positive aspiration biopsy preoperatively and we did not meet any thyroid malignancy in patients postoperatively. We think that thyroid pathologies may have an effect on parathyroidal operation techniques especially in endemic goiter regions.

\section{Conclusion}

Our findings indicate that bilateral intervention remains a successful management option without prior localization in patients with PHPT especially in an endemic goiter region. 


\section{References}

1 Rude RK: Hyperparathyroidism. Otolaryngol Clin North Am 1996;29:663-679.

-2 Heath H, Hodgson SF, Kennedy MA: Primary hyperparathyroidism: Incidence, morbidity and potential economic impact in a community. N Engl J Med 1980;302:189-193.

-3 Johanson H, Thoren L, Werner I: Hyperparathyroidism: Clinical experiences from 208 cases. Ups J Med Sci 1972;77:41-46.

-4 Preisman RA, Mehnert JH: A plethora of primary hyperparathyroidism. Arch Surg 1971; 103:12-13.

5 Boonstra CE, Jackson CE: Serum calcium: Survey for hyperparathyroidism: Results in 50,000 clinic patients. Am J Clin Pathol 1971;55:523526.

6 6 Kearns AE, Thompson GB: Medical and surgical management of hyperparathyroidism. Mayo Clin Proc 2002;77:87-91.

7 Chan FK, Koberle LM, Thys-Jacobs S, Bilezikian JP: Differential diagnosis, causes, and management of hypercalcemia. Curr Probl Surg 1997;34:445-523.

8 Siminoski K: Asymptomatic hyperparathyroidism: Is the pendulum swinging back? CMAJ 2000;163:173-175.

9 Diagnosis and management of asymptomatic primary hyperparathyroidism. National Institutes of Health Consensus Development Conference. October 29-31, 1990. Consens Statement 1990;8:1-18.

10 van Heerden JA, Farley DR: Parathyroid; in Schwartz SI (ed): Principles of Surgery, ed 7. New York, McGraw-Hill, 1999, pp 16941713.

11 Russell CF, Edis AJ: Surgery for primary hyperparathyroidism: Experience with 500 consecutive cases and evaluation of the role of surgery in the asymptomatic patient. Br J Surg 1982;69:244-247.

12 Rudberg C, Akerstrom G, Palmer M, Ljunghall S, Adami HO, Johansson H, Grimelius L, Thoren L, Bergstrom R: Late results of operation for primary hyperparathyroidism in 441 patients. Surgery 1986;99:643-651.

-13 Bergenfelz A, Lindblom P, Tibblin S, Westerdahl J: Unilateral versus bilateral neck exploration for primary hyperparathyroidism: A prospective randomized controlled trial. Ann Surg 2002;236:543-551.
14 Ozbas S, Pain S, Tang T, Wishart GC: Surgical management of primary hyperparathyroidism: Results of a national survey. Ann R Coll Surg Engl 2003;85:236-241.

15 Allendorf J, Kim L, Chabot J, DiGiorgi M, Spanknebel K, LoGerfo P: The impact of sestamibi scanning on the outcome of parathyroid surgery. J Clin Endocrinol Metab 2003;88: 3015-3018.

16 Blezikian JP: Primary hyperparathyroidism. Endocrinol Metab Clin North Am 2000;29: 465-478.

17 Chan AK, Duh QY, Katz MH, Siperstein AE, Clark OH: Clinical manifestations of primary hyperparathyroidism before and after parathyroidectomy: A case-control study. Ann Surg 1995;222:402-412.

18 Silverberg SJ, Shane E, Jacobs TP, Siris E, Bilezikian JP: A 10-year prospective study of primary hyperparathyroidism with or without parathyroid surgery. N Engl J Med 1999;341: 1249-1255.

19 Dokmetaş HS, Turkay C, Aydin C, Arici S: Prevalence of Helicobacter pylori in patients with primary hyperparathyroidism. J Bone Miner Metab 2001;19:373-377.

20 Tibblin S, Bondesson AG, Uden P: Current trends in the surgical treatment of solitary parathyroid adenoma: A questionnaire study from 53 surgical departments in 14 countries. Eur J Surg 1991;157:103-107.

21 Lorenz K, Nguyen-Thanh P, Dralle H: Unilateral open and minimally invasive procedures for primary hyperparathyroidism: A review of selective approaches. Langenbecks Arch Surg 2000;385:106-117.

22 Takami H, Sasaki Y, Ikeda Y, Tajima G: Intraoperative quick parathyroid hormone assay in the surgical management of hyperparathyroidism. Biomed Pharmacother 2002;56(suppl 1):26s-30s.
23 Dijkstra B, Healy C, Kelly LM, McDermott EW, Hill AD, O'Higgins N: Parathyroid localisation: Current practice. J R Coll Surg Edinb 2002;47:599-607.

24 Wang CA: Surgical management of primary hyperparathyroidism. Curr Probl Surg 1985; 22:1-50.

25 Davies M, Fraser WD, Hosking DJ: The management of primary hyperparathyroidism. Clin Endocrinol (Oxf) 2002;57:145-155.

26 Thomas SK, Wishart GC: Trends in surgical techniques. Nucl Med Commun 2003;24:115119 .

27 Goris ML, Basso LV, Keeling C: Parathyroid imaging. J Nucl Med 1991;32:887-889.

28 Miller DL, Doppman JL, Krudy AG, Shawker TH, Norton JA, Vucich JJ, Morrish KA, Marx SJ, Spiegel AM, Aurbach GD: Localization of parathyroid adenomas in patients who have undergone surgery. Part I. Noninvasive imaging methods. Radiology 1987;162:133-137.

-29 Miller P, Kindred A, Kosoy D, Davidson D, Lang H, Waxman K, Dunn J, Latimer RG: Preoperative sestamibi localization combined with intraoperative parathyroid hormone assay predicts successful focused unilateral neck exploration during surgery for primary hyperparathyroidism. Am Surg 2003;69:82-85.

30 Lee NC, Norton JA, Dainko EA, Duh QY, Latimer RG: Multiple-gland disease in primary hyperparathyroidism: A function of operative approach? Arch Surg 2002;137:896-899.

31 Carter AB, Howanitz PJ: Intraoperative testing for parathyroid hormone: A comprehensive review of the use of the assay and the relevant literature. Arch Pathol Lab Med 2003; 127:1424-1442.

32 Beck TM, Huber PR, Oertli D: Intraoperative parathormone measurement in patients with primary hyperparathyroidism: A prospective clinical study. Swiss Med Wkly 2003;133:206209.

- 33 Prager G, Czerny C, Ofluoglu S, Kurtaran A, Passler C: Impact of localization studies on feasibility of minimally invasive parathyroidectomy in an endemic goiter region. J Am Coll Surg 2003;196:542-548. 